\title{
Effects of a contralateral interference tone on auditory recognition*
}

\author{
EDWARD CUDAHY $\uparrow$ and BARRY LESHOWITZ $\div \dagger$ \\ Arizona State Liniversity. Tempe, Arizona 85281
}

\begin{abstract}
The effects of a contralateral interference tone on identification of the frequency of a brief signal were investigated. The signal was a 20 -msec sinusoid and was the same intensity as the $500-\mathrm{msec}$ interference tone. Changes in frequency discrimination were measured as a function of the temporal interval between signal and interference tone. Frequency discrimination was unaffected by the presence of a leading interference tone. However, the addition of a trailing interference tone produced a small (about $15 \%$ ) decrement in performance relative to discriminability measured in quiet. In contrast to the data and supporting theory of Massaro (1970). percent correct identification did not vary appreciably with intertone interval. The present data suggest that interference effects previously obtained with untrained Os are greatly attenuated for well-practiced Ss.
\end{abstract}

Recently, there have been several investigations of frequency discrimination of pure tones in the presence of a second tone (Massaro, 1970, 1971, 1972, 1973; Ronken, 1972: Leshowitz \& Cudahy, 1973). In the original work of Massaro, a single-interval identification paradigm was employed. On each trial, $S$ was presented one of two signals separated in frequency by $\Delta \mathrm{F} \mathrm{Hz}$, followed by or preceded by a longer duration interference tone. The task of the $O$ was to determine whether the signal was "high" or "low." Massaro's paradigm is analogous to temporal masking paradigms, except that Massaro's signal is far above masked threshold.

In a series of experiments, Massaro (1970, 1971, 1972 , 1973) demonstrated that a trailing tone causes a decrease in the identification of a brief $(20-\mathrm{msec})$ signal. $\mathrm{He}$ found that percent-correct identification as a function of the interval between termination of the signal and onset of the trailing interference tone was a monotonically increasing function. A leading interference tone, on the other hand, had no effect on identification performance relative to identification without the interference tone. From these results, Massaro hypothesized that the critical features of the replica of the signal tone were analyzed in a central information store before being transferred to a more permanent short-term store. This analysis takes time. Thus, he concluded that a tone arriving shortly after the signal tone would either terminate or disrupt processing

*This research was supported by United States Public Health Service Grant MH 20301 and by a contract from the Human Resources Laboratory, Flying Training Division, Williams Air Force Base, Arizona. A report of this work was presented at the meeting of the Psychonomic Society, St. Louis, November 1970.

† Requests for reprints should be sent to Edward Cudahy, Department of Psychology, Arizona State University, Tempe, Arizona 85281.

†† We thank M. J. Penner for critically reading an earlier draft of this manuscript. The present version paper has been greatly improved owing to the remarks of an anonymous reviewer and to the searching comments of Professor Charles S. Watson. of the signal, whereas a leading tone would not affect processing of the signal. Massaro estimated the time necessary to process the signal to be about $250 \mathrm{msec}$.

In support of Massaro's proposal of processing frequency information in a central store is his observation that a contralateral interference tone is as detrimental to performance as an ipsilateral tone. Massaro (1970) also showed that the amount of interference produced by a trailing tone was not related to the frequency separation between signal and interference tone. Both results are contrary to typical sensory masking findings and suggest that processing does not occur at the periphery of the auditory system.

More recently, Ronken (1972) and Leshowitz and Cudahy (1973) used a two-interval forced-choice. procedure in an examination of the problem. They both found that the addition of an ipsilateral trailing interference tone caused a decrement in frequency discrimination of a $10-\mathrm{msec}$ signal. The addition of a leading interference tone either enhanced performance relative to discriminability in the quiet or had no effect. In addition, Leshowitz and Cudahy (1973) found that the interference effects caused by a trailing tone were dependent on the duration of the signal. They found little or no decrement in performance when the signal was $20 \mathrm{msec}$ in duration. Moreover, in contrast to Massaro's finding, a trailing interference tone presented to the contralateral ear had no effect on frequency discrimination, irrespective of the duration of the signal. Leshowitz and Cudahy's (1973) results with a contralateral interference tone are counterindicative of a central information store. The results suggest that the interference can be attributed to peripheral mechanisms, as in sensory masking. Some caution must be observed in accepting this conclusion in view of the differences in procedures between Massaro's (1970) studies and Leshowitz and Cudahy's (1973) studies. In light of the importance of the theoretical question of a central store for processing tonal frequency information, it was decided to replicate Massaro's (1970) single interval contralateral-ear condition. 


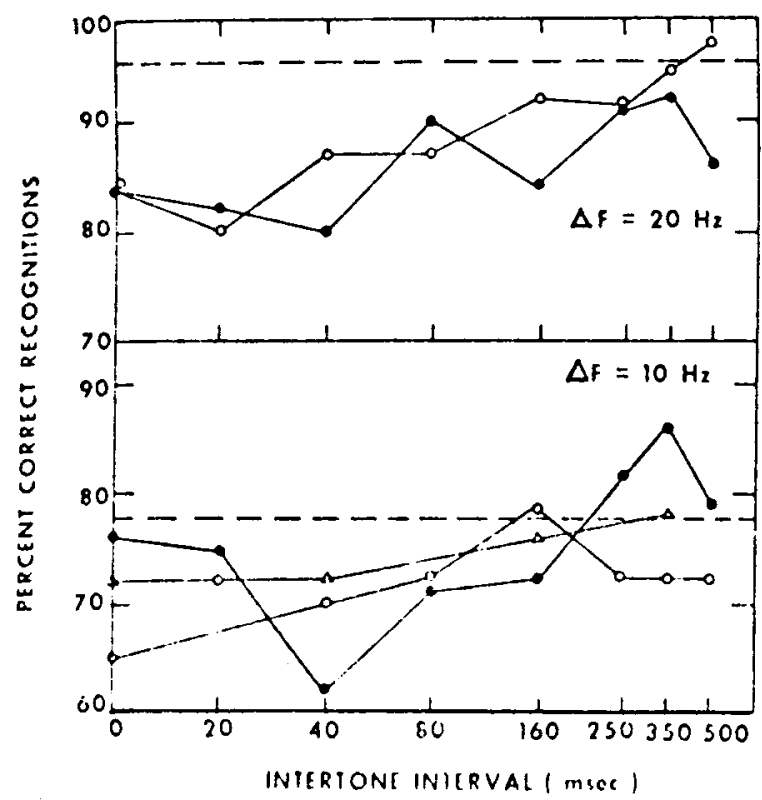

Fig. 1. Recognition as a function of the intertone interval between signal and interference tones. The high and low signal tones were $f_{s}+\Delta F / 2$ and $f_{s}-\Delta F / 2$, where $f_{s}$ was $820 \mathrm{~Hz}$. The frequency separation, $\Delta \mathrm{F}$, is indicated in the figure. Three masking conditions are represented by different symbols: backward masking/signal-ear random, o; forward masking/signal-ear random, •: backward masking/signal-ear specified, $\therefore$. The dashed line represents performance measured in silence. Each point is based on 100 observations. Data for S B.B.

\section{EXPERIMENT I}

\section{Method}

\section{Subjects}

The Ss were all undergraduates and were paid $\$ 2 / \mathrm{h}$ for their services, except E.C. The Ss were experienced Os in frequency discrimination and had three sessions of practice before the present experiment.

\section{Procedure}

Massaro's (1970) single-interval contralateral-ear condition was repeated. In addition to Massaro's trailing-interference-tone condition, frequency recognition in the presence of a leading interference tone was examined. In the trailing-interference-tone condition, $500 \mathrm{msec}$ after a warning light. a $20-\mathrm{msec}$ signal was presented randomly to either ear. The probability of presentation to a given ear was .5. After an intertone interval of $0,20,40,80,160,250.350$. or $500 \mathrm{msec}$, a $500-\mathrm{msec}$ interference tone was presented to the ear contralateral to the signal ear. The intertone interval was measured from termination of the signal to onset of the interference tone. Intertone interval was randomized from trial to trial. Each intertone interval occurred with a probability of .125 . In the leading interference-tone condition, the order of the signal and interference tones was reversed. Everything else remained the same. The intertone interval for the leading-interference-tone condition was measured from termination of the interference tone to the onset of the signal.

For both leading and trailing tone conditions, the interference tone was $999 \mathrm{~Hz}$. All tones were $80 \mathrm{~dB}$ SPL. Two tones separated in frequency by $\Delta \mathrm{F}: \mathrm{Hz}$ served as test tones. The frequencies of the high and low test tones were $\left(f_{s}+\Delta F / 2\right)$ and $\left(f_{s}-\Delta F / 2\right)$, respectively, where $f_{s}$ was $820 \mathrm{~Hz}$. The S's task was to label the test tone as either high or low. Knowledge of the correct response was provided on each trial. The frequency separations, $\Delta \mathrm{F}$, were selected for each $\mathrm{S}$ such that the probability of correct recognition in the quiet was about.80. In a second study. $\Delta F$ was chosen such that $P(c)$ was about .90 in the quiet.

A listening session consisted of eight blocks of 200 trials. In a block of trials. $\Delta F$ was fixed. Each block of trials was devoted to a given condition. Two conditions were examined: signal ear randomized, leading masker; signal ear randomized, trailing masker.

\section{Results and Discussion}

Figures 1-4 present the results of the first experiment for individual Ss. The proportion of tones correctly recognized is plotted as a function of the intertone interval for leading-interference-tone (closed circles) and trailing-interference-tone (open circles) conditions. Very little, if any, decrement was obtained in the leadinginterference-tone condition. The results from all of the Ss presented in Figs. 1-4 reveal that the addition of a trailing tone produced a small decrement in performance. The decrement is about $15 \%$ relative to performance in the quiet condition. Although the effect of intertone interval is small, there is a suggestion that level of performance increases with signal interference-tone delay for both leading- and trailing-tone conditions.

The results presented in Figs. 2, 3, and 4 show a small,

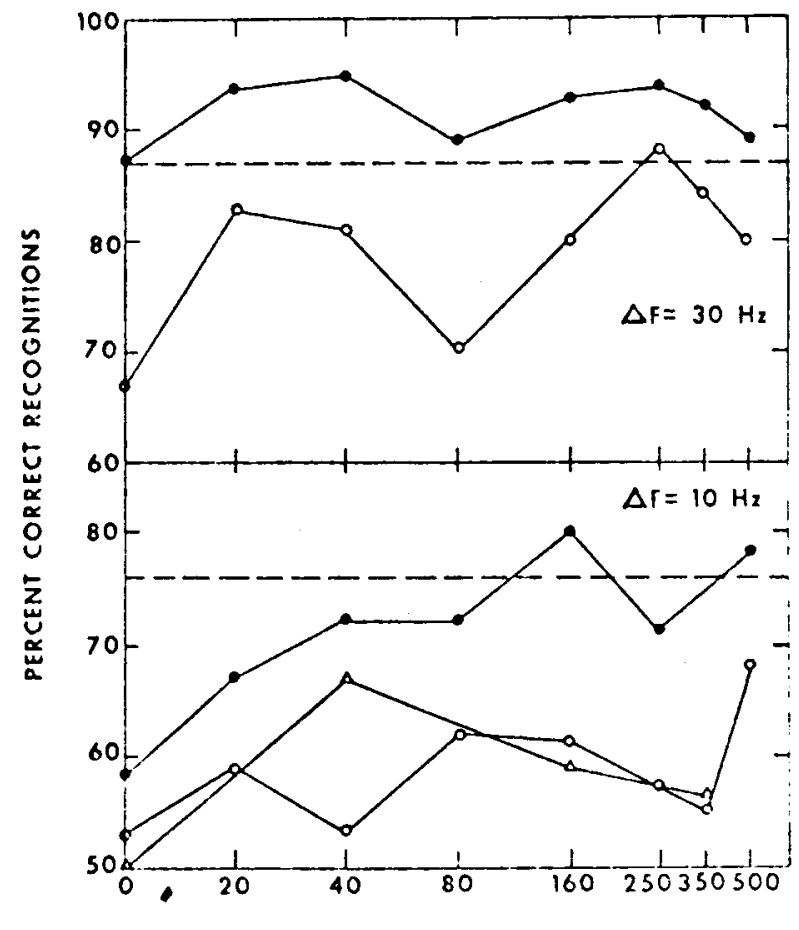

INTERTONE INIERVAL (msec)

Fig. 2. Same as Fig. 1. Data for S J.R. 
but consistent, difference in performance between leading- and trailing-interference-tone conditions. For three of the four Ss, identification of tones in the presence of a leading masker exceeds that obtained with a trailing masker. The data of S B.B., presented in Fig. 1, failed to show a comparable asymmetry. These data provide some support for Massaro's hypothesis of interruption of central processing by the contralaterally presented trailing interference tone. However, there exists an alternative explanation of the difference between leading- and trailing-interference-tone conditions. Let us consider the task of a $S$ who is required to identify the frequency of a brief signal followed by a contralateral interference tone. The ear receiving the signal is chosen at random from trial to trial. Suppose, on a given trial, $S$ is monitoring the nonsignal ear. Attention probably cannot be switched to the signal ear by the time the signal is terminated, since the duration of the signal is only $20 \mathrm{msec}$. Thus, having never "heard" the signal, $\mathrm{S}$ would have to guess as to whether the signal was high or low. Now contrast the above condition with the leading interference-tone condition in which the $500-\mathrm{msec}$ contralateral masker precedes the signal. The $S$ now has knowledge of which ear will receive the signal and can, therefore, devote his full attention to the signal channel. A simple channel model of this sort can account for the performance decrement observed in the trailing-interference-tone condition.

\section{EXPERIMENT II}

Experiment II was conducted in an effort to test the channel hypothesis. The signal was always presented to one ear and the trailing-interference tone to the other ear. Except for always presenting the signal to the same ear, and except for the reduction of intertone intervals to four, all experimental procedures in Experiment II

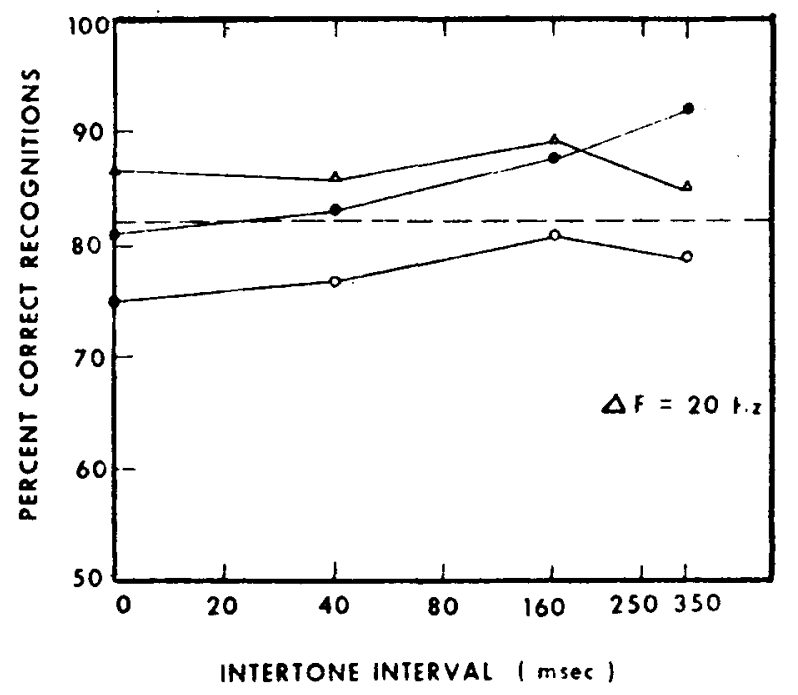

Fig. 3. Same as Fig. 1. Data for S R.R.

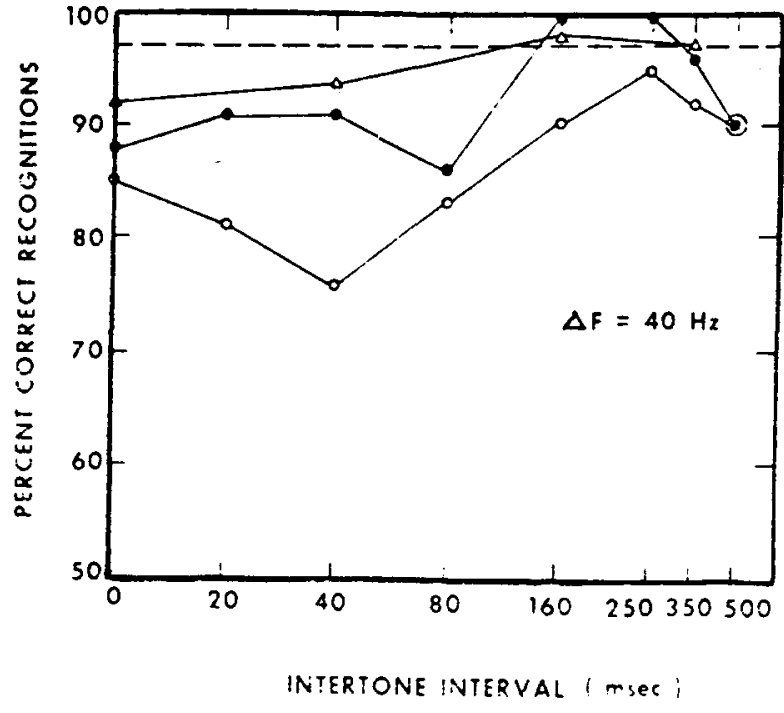

Fig. 4. Same as Fig. 1. Data for S E.C.

were identical to those of the previous experiment. During an experimental session, the signal was always presented to one ear, the trailing tone to the other ear. Four intertone intervals, randomized over trials, were tested during each segment: $0,40,160$, and $350 \mathrm{msec}$. All four Ss from the previous experiment participated in this experiment. All Ss performed the experiment at only one performance level.

The results of the second experiment (triangles) are shown in Figs. 14. S B.B., whose performance is shown in Fig. 1, showed no difference in performance between leading and trailing interference-tone conditions in Experiment I. The performance of two of the three remaining $S s$ is in agreement with the channel hypothesis described earlier. For Ss R.R. and E.C., specifying the signal led to an improvement in performance relative to the signal-ear-randomized condition conducted in Experiment I (see Figs. 3 and 4). For the third S, J.R., as can be seen in Fig. 2, specifying the signal ear had no effect on performance.

\section{GENERAL DISCUSSION}

In summary, our attempts to replicate Massaro's finding of a large performance decrement in identification of frequency of tones in the presence of a contralateral trailing interference tone were only partially successful. In agreement with Massaro's results, for three of the four Ss, a small, but consistent, difference between leading and trailing interference-tone conditions was obtained in Experiment $I$.

The present data and those reported by Massaro display two striking discrepancies. First, the decrement caused by a trailing tone observed in the present work was much smaller than that reported by Massaro. ${ }^{1}$ Second, the graphs of percent correct as a function of intertone interval presented here are not increasing 


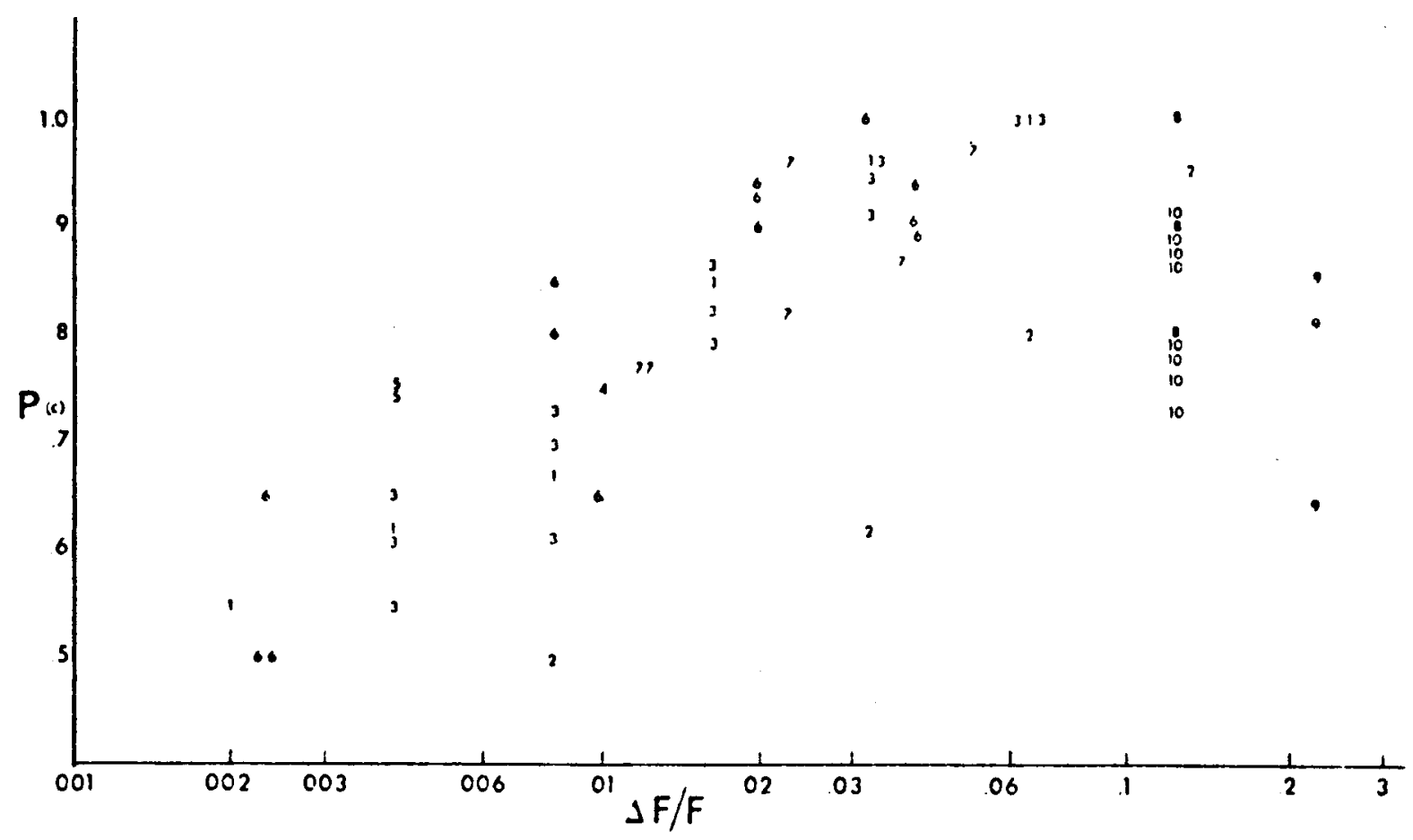

Fig. 5. Comparison of results of several studies on frequency discrimination. Individual symbols refer to performance obtained in several studies. Information in parentheses corresponds to signal frequency, signal duration, psychophysical method, and individual or group data, in that order: (1) Ronken, 1971 (1,000 Hz, $16 \mathrm{msec}, 2 \mathrm{AFC}$, ind.); (2) Ronken, 1972 $(1,000 \mathrm{~Hz}, 10 \mathrm{msec}, 2 \mathrm{AFC}$, group); (3) Ronken, 1972 (1,000 Hz, $10 \mathrm{msec}, 2 \mathrm{AFC}$, ind.): (4) Liang and Chistovich, 1961 $(1,000 \mathrm{~Hz}, 20 \mathrm{msec}$, adjustment, ind.): (5) Henning, 1969 (1,000 Hz, $20 \mathrm{msec}, 2 \mathrm{AFC}$, ind.): (6) Leshowitz and Cudahy, 1973 ( $820 \mathrm{~Hz}, 10 \mathrm{msec}, 2 \mathrm{AFC}$, ind.): (7) Cudahy and Leshowitz, 1973 (820 Hz, $20 \mathrm{msec}$, identification, ind.); (8) Massaro, 1970 ( $820 \mathrm{~Hz}, 20 \mathrm{msec}$, identification, ind.): (9) Massaro, $1970(540 \mathrm{~Hz}, 20 \mathrm{msec}$, identification, ind.); (10) Massaro, 1970 (820 Hz, 20 msec, identification, ind.).

functions of signal masker delay as Massaro's perceptual processing arguments would predict. Indeed, close inspection of Massaro's own results for contralateral masker conditions reveal a similar effect. As can be seen in Figs. 2 and 3 of Massaro (1970), performance never reached near-perfect levels, even for long intertone intervals. For five of the eight conditions shown in Figs. 2 and 3, for masker delays greater than $350 \mathrm{msec}$, percent-correct recognition was iess than .8. Both Massaro's original work and the present replication of the contralateral masking condition fail to support Massaro's estimate of $250 \mathrm{msec}$ as the time required to complete processing.

Differences in the ability of Ss are undoubtedly partially responsible for the discrepant findings. As indicated above, in the contralateral condition. Massaro's Os were performing at moderately low levels [i.e., $\mathrm{P}(\mathrm{c})=$ .8] for differences in signal frequency of $100 \mathrm{~Hz}$ at long masker delays. In the present work, above-chance performance was obtained at frequency separations of $10 \mathrm{~Hz}$.

Further support for the position that there is something unusual about Massaro's Ss comes from a direct comparison of Massaro's data with results in the literature on frequency discrimination. For purposes of comparison, it is assumed that. had Massaro measured performance in the quiet, performance would not have been significantly different from his measurements for $\Delta \mathrm{T}=500$. Figure 5 presents a summary of the data on frequency discrimination of brief tones. It is apparent that, although data on frequency discrimination display an uncomfortable amount of variability, Massaro's data are roughly a log unit less sensitive than everyone else's. This difference does not stem from the particular psychophysical method. It may be that Massaro's Ss were not as experienced as those employed in previous investigations. However, in light of the gross differences between Massaro's results and the results of all other investigations, it is hard to imagine that difference in training is the entire explanation.

In conclusion, the present study does not provide strong support for a cognitive perceptual model of pitch perception. With well-practiced Os, we were unable to demonstrate appreciable interference effects for contralateral maskers. At most, there was about a $15 \%$ decrement in performance relative to discriminability measured in quiet. The present finding of an improvement in performance for the signal-ear-specified condition indicates that frequency discrimination of brief signals is especially difficult when a randomized-ear procedure is employed. And finally, our earlier investigation has shown that interference effects 
produced by contralateral trailing tones are greatly attenuated when a two-alternative forced-choice procedure is employed (Leshowitz \& Cudahy, 1973).

\section{REFERENCES}

Henning, G. B. A comparison of the effects of signal duration on frequency and amplitude discrimination. In R. Plomp and G. Smoorenburg (Eds), Frequency analysis and periodicity detection in hearing. Leiden: Sitjhoff, 1970.

Leshowitz. B.. \& Cudahy, E. Frequency discrimination in the presence of another tone. Journal of the Acoustical Society of America, 1973, in press.

Liang, C., \& Chistovich, L. A. Frequency-difference limens as a function of tonal duration. Soviet Physical Acoustics, 1961, 6, 75-80.

Massaro, D. W. Preperceptual auditory images. Journal of Experimental Psychology, 1970, 84, 411-417.

Massaro, D. W. Effect of masking tone duration on preperceptual auditory images. Journal of Experimental Psychology, 1971, 87, 146-148.

Massaro, D. W. Preperceptual images, processing time and perceptual units in auditory perception. Psychological Review, $1972,79,124-145$.

Massaro, D. W., \& Kahn, B. J. Effects of central processing on auditory recognition. Journal of Experimental Psychology, $1973,97,51-58$.

Ronken, D. A. Some effects of bandwidth-duration constraints on frequency discrimination. Journal of the Acoustical Society of America, 1971, 49, 1232-1242.

Ronken, D. A. Changes in frequency discrimination caused by leading and trailing tones. Journal of the Acoustical Society of America, 1972, 51, 1947-1950.

\section{NOTE}

1. Unfortunately, a quantitative estimate of the discrepancy cannot be made. Since Massaro failed to measure performance in the quiet, we do not know the magnitude of the performance decrement he observed. Massaro implies that his effect is much larger than the $15 \%$ decrement obtained in the present study.

(Received for publication A pril 10, 1973; revision received June 17,1973 .) 